\title{
Process Reengineering using Activity Theory and Domain Mapping Matrix Method in Delivering Public Construction Projects
}

\author{
Alsuwaidi, Hadif ${ }^{\mathrm{a}}$, Venkatachalam, Senthilkumar ${ }^{\mathrm{b} *}$ \\ ${ }^{a}$ Graduate Student, University of Sharjah, Sharjah, United Arab Emirates \\ ${ }^{b}$ Assistant Professor, University of Sharjah, Sharjah, United Arab Emirates
}

\begin{abstract}
The complexity of modern construction projects has been increasing due to the increased number of design disciplines, stakeholders, process and tools. In public project delivery, these complexities are further increased due to the existence of additional bureaucratic procedures. These decade old processes and the bureaucratic procedures left with dysfunctionalities, redundancies and non-value adding process wastes to the project outcome. This in-turn has a significant adverse knock on effect on the public project delivery in time, cost and quality outcomes. Hence, understanding the existing interactions and its complexity among the project delivery elements such as process, people and deliverables in public project delivery are paramount important to modifying the same to obtain the desired outcome based on the dynamic industry needs. In this proposed research, an example public project delivery department's existing workflow was captured using activity theory. Further, the existence of various people, process, deliverables and their interactions in the project delivery process were identified through an IDEF0 models. The identified project delivery elements and its interactions were then analyzed using a Multi Domain Mapping (MDM) method to evaluate against process dysfunctionalities, redundancies and wastes. In addition, the study also proposed an improved process flow by eliminating the above said discrepancies through a structured business process-reengineering framework. Further, the study validates the proposed framework through expert interview on the modifications made in project delivery elements. The proposed framework will be a guideline/ reference for similar business process reengineering exercise towards a public project delivery process in this region or in a similar context.

(C) 2019 The Authors. Published by Budapest University of Technology and Economics \& Diamond Congress Ltd.

Peer-review under responsibility of the scientific committee of the Creative Construction Conference 2019.

Keywords: Process Reengineerin;, Public Project; Multi Domain Mapping Matrix; Activity Theory.
\end{abstract}

\section{Introduction}

Modern construction projects delivery methods are complex and multidisciplinary in nature; this demands seamless interactions of various simultaneous processes among different project stakeholders. The simultaneous execution of various project processes poses challenges on its delivery. Further, these projects are also characterized with inefficient project delivery in terms of cost and time[1,2]. Most of these inefficiencies are attributed towards the differing objectives of various stakeholders in contrast with the project outcomes [3]. Further, the decade old bureaucratic processes along with traditional project delivery methods create a complex socio-technical issues while delivering the public projects and inheriting the process wastes and redundancies. This complexity related issues can be attributed from aspects such as the organizational structure, procedures, policies and techniques [3]. Further, these complexities are pulling back the planned flow of the projects and negatively affecting the management and coordination capabilities of projects stakeholders [4]. Understanding the existence of these project complexities and removing the process wastes 
Venkatachalam,Senthilkumar / Proceedings of the Creative Construction Conference (2019) 057 https://doi.org/10.3311/CCC2019-057

and redundancies is important to improve the project efficiency and performance. Hence, the current study took a government entity called as "SDPW" (named for this manuscript readability purpose only, there is no such name exists), that is responsible of delivering public projects in UAE as the study case. SDPW was formed in 2000 and it is mandated to study, design, implement and maintain government-building projects to improve the public services and infrastructure in a provincial government. In order to maintain and deliver the public building projects, the entity had established three main departments: 1. Chairman Office (CO), 2.Building Projects Department (BPD) and 3.Contract and Tendering Department (CTD). CO is responsible for approving project budget, design and payments. BPD has two sub sections, which are design section and supervision section; it is responsible of designing and supervising the project respectively. CTD is responsible for analysing the tender and preparing contract document. Each department has its own structured processes through which the projects are delivered in stages. Even though, there are enough resources and the existence of a clear and well-defined process flow framework, SDPW is facing challenges such as delay and cost overruns while delivering the public projects. A pilot study was conducted to validate the same; the study took 33 projects among the 136 projects delivered during the past 3 years as a sample. This sample analysis showed that 20 out 33 projects were facing cost overrun and on the other hand, 30 out of 33 projects underwent delay. There might be many reasons attributed towards these project delivery outcomes. In order to investigate the reasons towards these inefficiencies, a follow-up of 12 pilot interviews were conducted with the respective project managers of these affected projects. The interview revealed that there were redundant processes and process wastes which played a significant role on the delay and cost overruns in all those affected projects commonly, it was also been informed that the current pubic project delivery process to manage people, processes and deliverables have dysfunctionalities and inefficiencies. Alleviating the same and improving the public project delivery efficiently is of paramount important. Hence, this paper propose a solution approach for the problem identified through the following sequences. First, the existing SDPW process flow is captured using a simple flow chart. Then, the activity theory was used to capture the interrelated interaction of process people and deliverables of this complex system of public project delivery. These interrelated interactions among various activities were described in a detailed, using IDEF0 model. With the use of the developed IDEF0 model for each of the project stage, an MDM model was generated to visualize the relationship among the various project processes stakeholders and tools. The MDM analysis identify the dysfunctionalities redundancies and process wastes during the project delivery processes. The proposed framework will be a guideline/ reference for someone, who is willing to perform similar business process reengineering exercise for their public project delivery process. The paper has 7 sections, the following section critically review the literatures on the process modelling tools, section 3 explains the adopted study methodology, Section 4, 5 and 6 describe the data manipulation and analysis of current project delivery processes and the proposed reengineered project delivery processes. The summery and discussions are presented in section 7 .

\section{Literature Review}

\subsection{Business Process Reengineering}

Business process can be defined as collection of activities whose final aim is the production of a specific output that is of value to the customer [5]. Davenport and Short described the business process based on three dimensions; Entity: is where the process is taking place, Objects: the process results is object oriented, Activities: processes can be in different types like managerial, operational etc. [6]. The paper also described BPR as redesign of the processes and workflow between organizations in order to achieve specific goals. Hammer et al., stated that BPR is the way of achieving dramatic improvements in a company's performances in quality, cost, speed etc., by radical redesign of its processes [5] and [7]. BPR has been described as a revolution in business administration in which it renovates the operational processes to improve business performance[8]. Therefore, construction process reengineering can be defined as the redesign of existing processes in order to achieve project success. The advent of modern IT tools further defines the BPR as to efficient automation of complex processes using the IT capabilities. Implementation of BPR is not only limited to the companies that are having bad performance but also the companies which seeks performance enhancements. Hammer and Champy identified three type of companies that are needed to implement BPR: 1 . 
Venkatachalam,Senthilkumar / Proceedings of the Creative Construction Conference (2019) 057 https://doi.org/10.3311/CCC2019-057

Company that is facing problems in its performance and its expenses is less than its revenue, 2. Company that are not facing any bad performance but its manager anticipating that problem is nearby to occur, 3 . Company that are highly performed but it is looking forward to developing the lead over its competitors [5]. Hence, BPR becomes inevitable, perennial, and iterative exercise at some regular intervals. It is also reported that BPR has advantages in solving problems and improving the internal system in the companies [9]. However, BPR has to be implemented in an accurate manner to ensure its efficiency. Hammer and Champy identified the major activities that an organization has to carry out to properly implementing BPR; Identifying, delineating and modelling the current work flow, then analyse it for deficiencies, after that new process should be proposed and finally the proposed process has to be implemented in terms of new technical terms, organizational role and responsibilities [5].

\subsection{Business Process Reengineering Tools}

The tools and techniques that can be deployed during various stages to implement the BPR varies on the purposes of the BPR stages. Aguilar-Savén listed various tools and techniques of BPR and classify them according to their use, application, advantages and disadvantages[9]. Further, this has been referred as a guide to the practitioners and academics while choosing the best tool based on their requirements. The RID and Gantt chart techniques are describing the flow of the activities in a matrix based representation. RID shows the role of individuals in each activity while Gant chart shows the duration of the activities, both tools are somehow difficult in the analysis and modification of the existing diagrams [9]. To overcome the challenges of these tools, this research used a combination of tools. The following subsections described the tools used in this study.

\subsubsection{Activity Theory}

Activity Theory is an approach that mostly used in analysing and understanding complex systems and their interrelated interactions [10]. Activity theory is a framework that aims to beat dysfunctionalities of micro and macro, mental and material, observation and intervention in analysis and redesign of work [11]. It can be used to identify and conceptualize the collaborative activities of project team and as a framework in the delivery process [10,11]. Leont'ev described that activity is composed of subject, objects, actions and operations [12]. A subject is a person or a group engaged in an activity. An object is held by the subject and motivates activity, giving it a specific direction, there is always a need or a desire is standing behind the object. Actions are goal-directed processes that must be undertaken to fulfil the object. They are conscious and different actions may be undertaken to meet the same goal. There are six principles of activity theory stated in the research conducted by Version [13]; the most fundamental and the first principle is the unity of the consciousness and activity "Consciousness" in this expression means the human mind as a whole and is a special component that relates human interaction with its environment [13]. The second principle is object-oriented. This principle specifies the activity theory approach to the environment with which human beings are interacting. This environment consists of entities that combine all kinds of objective features, including the culturally determined ones, which, in turn, determine the way people act on these entities. The third principle is "hierarchical structure of activity." Activity theory differentiates between processes at various levels taking into consideration the objects to which these processes are oriented. The fourth principle according is the internalization/externalization [14]. This principle is describing mechanisms underlying the originating of mental processes. It states that mental processes are derived from external actions through the course of internalization. The fifth principle is mediation. This principle states that human activity is mediated by external and internal number of tools. The last principle is the principle of development. It gives an opportunity to conduct thorough scientific analysis of complex phenomena while avoiding mechanistic oversimplifications [11]. Activity theory showed its effectiveness in solving problems that related to lack of coordination and communication between stakeholders in an activity system by analysing and modelling of the contradiction in the system [15]. Further this theory provides framework for guiding the system through process changes by dealing with contradictions and disturbances within and between the constitutes of the system, and enabling the adaption of new situations $[16,17]$.

\subsubsection{Integration Definition for Function Modeling (IDEF0)}

Integration Definition for Function Modeling (IDEF0) models are consider as the most commonly used tools by engineers to capture and analyze the complexity of a system and study the relationship of system component [18]. IDEF0 has been developed as a standard representation of an organized activity and processes [19]. IDEF0 models are characterized by its ease in understanding and its versatility towards its modification capabilities, it is well defined and 
Venkatachalam,Senthilkumar / Proceedings of the Creative Construction Conference (2019) 057 https://doi.org/10.3311/CCC2019-057

structured and it can be used for analyzing up to an in depth details [18]. IDEF0 has a notational construct called ICOM (Input-Control-Output-Mechanism). IDEF0 supports process modelling by decomposing higher-level ICOMs into more detailed models that depict the hierarchical decomposition of activities [20].

\subsubsection{Multiple Domain Matrix (MDM)}

Design Structure Matrix (DSM) tool is commonly used to analyse and represent complex system and especially used for decomposition and integration of systems[21]. The advantages of DSM have increased its usage in different sector and purposes including product development, project planning, project management, systems engineering, and organization design [21]. The DSM approach entails the decomposition of a system into its constituents at various hierarchical levels, identification of the relationships among the elements, analysis to understand the system's behavior [22]. The extension of the DSM is the multi-domain matrix (MDM). It is a rectangular matrix mapping between different DSM domains [23]. MDM has the ability to represent numerous networks and capture more than one relationship types at the same time [24]. MDM showed its effectiveness and advantageous as a process modeling tool through its analysis capability [23,24]. It has a capability to capture the system complexity in a most realistic way [25]. Hence, to identify and capture the interrelationships among the various domains through MDM in this study.

\subsection{Study Case}

This study takes SDPW as a case; hierarchal structure of SDPW is shown in Fig. 1. The hierarchal structure shows that there is a manager for both CTD and BPD. Furthermore, BPD has two sections, which are; Design and Supervision, each section has its own head. The employees in design section consist of Architecture Engineers, MechanicalElectrical-Plumbing (MEP) Engineers and Draftsmen. In supervision section there are Supervision engineers and MEP engineers, while in the CTD there are contract and MEP engineers and quantity survivor. SDPW business process is complex as it involved many stakeholders and its process flow had been developed decades back before the advent of the modern tools such as IT applications and management.
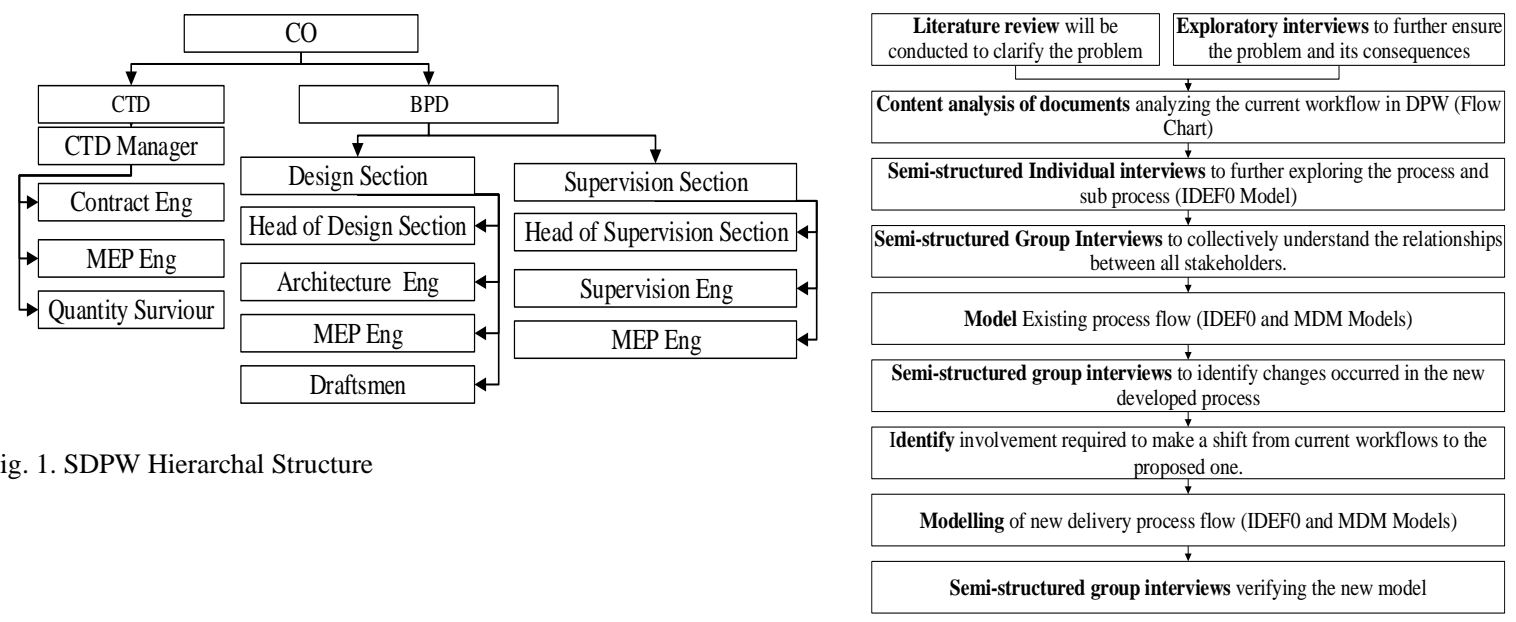

Fig. 1. SDPW Hierarchal Structure

Fig. 2. Research Method

\section{Adopted Research Method}

Fig.2. illustrates the steps adopted in this research. As the first step, the study sampled 33 numbers of recent projects to validate the need for the study followed by the extensive literature review to understand and explore the subject area. Pilot interviews were conducted to extracts the information such as the organizational structure, functions, rules etc., about different departments in SDPW. This further assist to assess the current state of public project delivery processes. The pilot interviews were conducted with the managers of the three departments overlooking the public project delivery in SDPW. The existing process flow was captured and analysed through series of individual and group 
Venkatachalam,Senthilkumar / Proceedings of the Creative Construction Conference (2019) 057

https://doi.org/10.3311/CCC2019-057

interviews with the relevant stakeholders. There were 12 individual interviews representing all stakeholders and the group interview was conducted with the group consist of head of design section, head of supervision section, 2 contract engineer, a quantity survivor, a supervision engineer, an architecture engineer and 3 MEP engineers; one from CTD department and one from each section in BPD department. The number of the individuals participated in group study was within the limit of study group stated in the research conducted by Stewart et al [27]. The existing process flow has been modelled using IDEF0 method. The analysis of the existing process is done through DSM/MDM method. After analysing the processes to remove the dysfunctionality and non-value adding project elements, group interview was conducted to identify the changes occurred. Then the modification of the existing project elements to alleviate the dysfunctionalities, redundancies and wastes are capture in the modified MDM and IDEF0 models. Validation of the proposed project delivery framework was evaluated by the group interviews consists of 12 respondents. Due to the limitations on the paper length only the CTD process is been explained in the following sections to demonstrate the proposed process reengineering method.

\section{Analysis of Existing Process Flow}

Based on the developed process flow chart and the activity theory representation for each of the project delivery processes steps, the IDEF0 model was created. The validity of the IDEF0 model was ascertained through a series of structured interviews about all these system components by the relevant stakeholders in the CTD department. Fig. 3 shows the IDEF0 model of the CTD department system components.

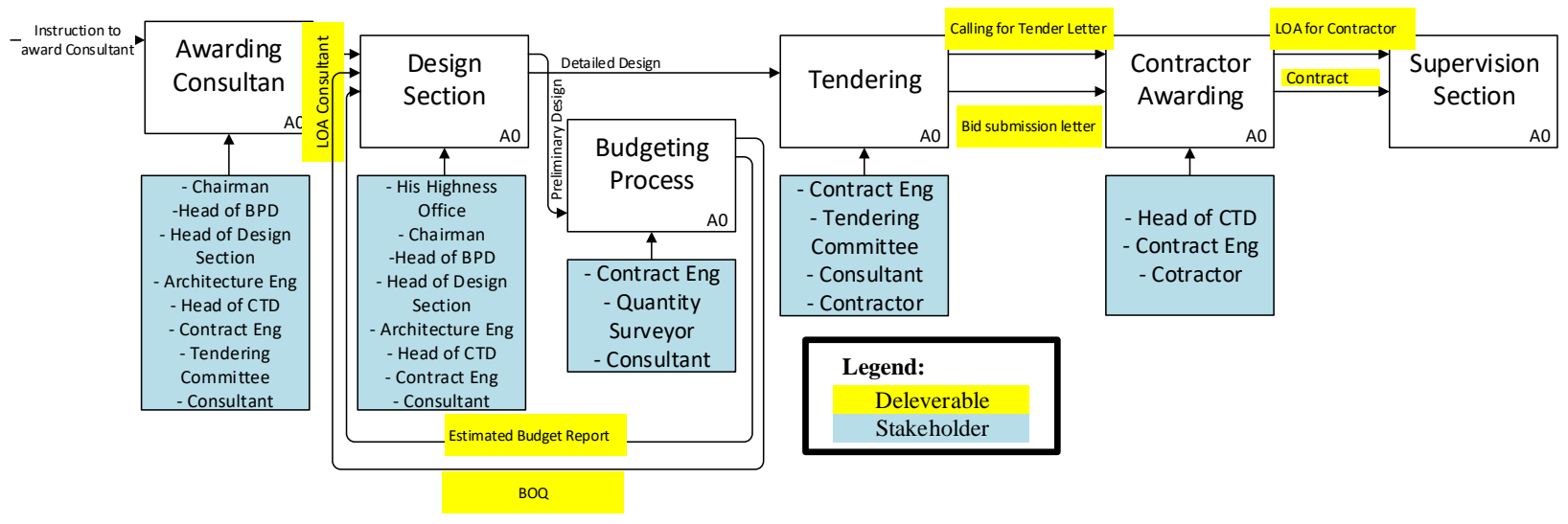

Fig. 3. IDEF0 for Existing Process Flow

The model shows that the CTD department is responsible for 7 deliverables during their project delivery stage. There are 11 different stakeholders involved in 11 sub-processes to deliver these 7 deliverables. It is also showed that the process of CTD is interrelated with the process in BPD design section and BPD deliverables. To further analyze these captured processes and identifying the relationship between the processes, deliverables and stakeholders, an MDM model has been developed. MDM captured the existence and the type of relationships between deliverables stakeholders, deliverable-processes, processes- stakeholder. The existence of relationship was categorized as; $0=$ no relation, $1=$ procedural relation and $2=$ logical relation. The procedural relationship are to exercise the bureaucratic authority to the subordinate. However the logical relationship are to be observed without compromise to achieve the desired project outcome. To determine the same, a set of standard 5 questions have been asked to the respondents based on which, the existence and type of the relationship had been determined. The question asked to the respondents are as follows; 1 . Is this deliverable /stakeholder necessary to perform this task/to proceed next? 2. Is this procedural / logical relationship? 3. How can this deliverable /stakeholder be managed? 4. Can the sequence of this deliverable /stakeholder be changed? 5. What will happen if this deliverable is deleted? and/or the stakeholder not involved? Furthermore, the MDM model also captured the repetitions or the delay incurred by each stakeholder against each of the processes and there by the deliverables as shown in the red diagonal cells in Fig.4. 
Venkatachalam,Senthilkumar / Proceedings of the Creative Construction Conference (2019) 057 https://doi.org/10.3311/CCC2019-057

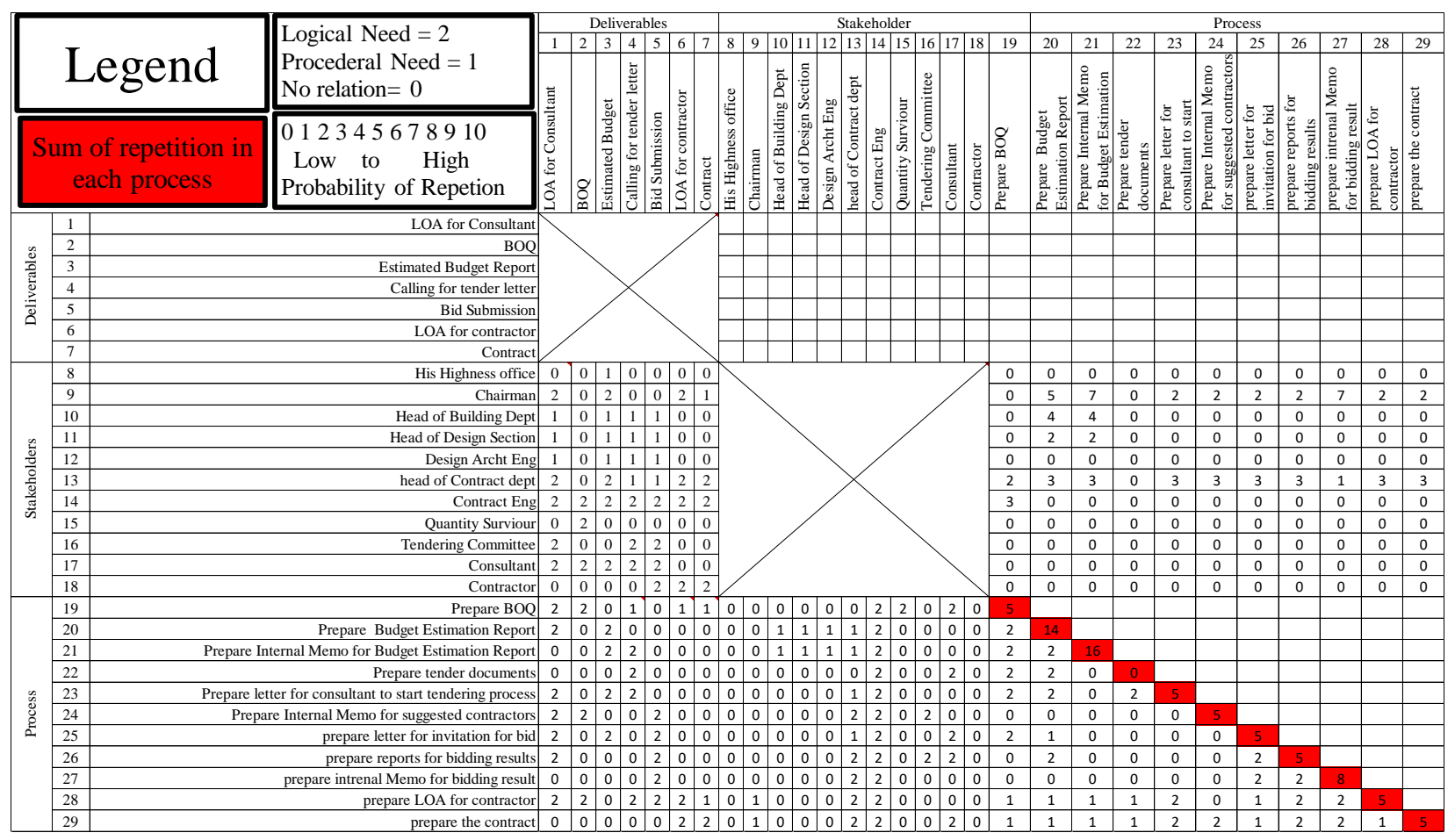

Fig. 4. MDM model current- status

\section{Identification of Process Waste, Redundancy and Dysfunctionality.}

The analysis of the MDM started with the Process DSM as shown in the figure 4. The diagonal represents the repetition of the processes by various stakeholders captured in the DMM of Stakeholders Vs Processes. The most repetition and there by the delay was recorded in the processes called "preparing budget estimate and prepare internal memo to budget estimation" as shown in cells (read as Row and Colum numbers respectively) $(20,20)$ and $(21,21)$ respectively. The BPD manager and head of design section are responsible stakeholders for the same, since both stakeholders are external parties (from outside of the CTD department) and causing the processes to be repeated 6 times. By examining the existence and the type of the interrelationships between these stakeholders and the process, it is clear that there exists a relationship and is considered as a procedural relationship as shown in cells $(20,10),(20,11),(21,10)$ and $(21,11)$ (which is part of a bureaucratic setup made while the SDPW was established). However, neither the process nor the stakeholders adds value to the processes and its deliverables, except as an another bureaucratic reporting system. Hence, these stakeholders and their relevant processes should be removed from the process loop to avoid delay. Similarly, all the processes, its relationship with the stakeholder and its deliverables were investigated against the existence of the process inefficiencies such as process wastes, redundancies and dysfunctionalities. These identified inefficiencies were then reengineered through changing the process, policies and the responsibilities.

\section{Reengineered Process Flow}

Reengineering the processes as described in the previous section helped to reduce the number of repetition in the process. Moreover, by changing the policy in signing the Letter of Award (LOA) and contract for the contractor by giving the CTD manager the authorization to sign instead of the chairman would help in reducing the redundancies and time delay. The new MDM model was created based on the elimination of the process waste, redundancies and dysfunctionality in CTD department as shown in Fig.5. The same was highlighted with green shade in the cells. Though the deliverables of the modified and the existing processes are same, the stakeholders and their redundancies in terms of procedural process wastes have been removed. 


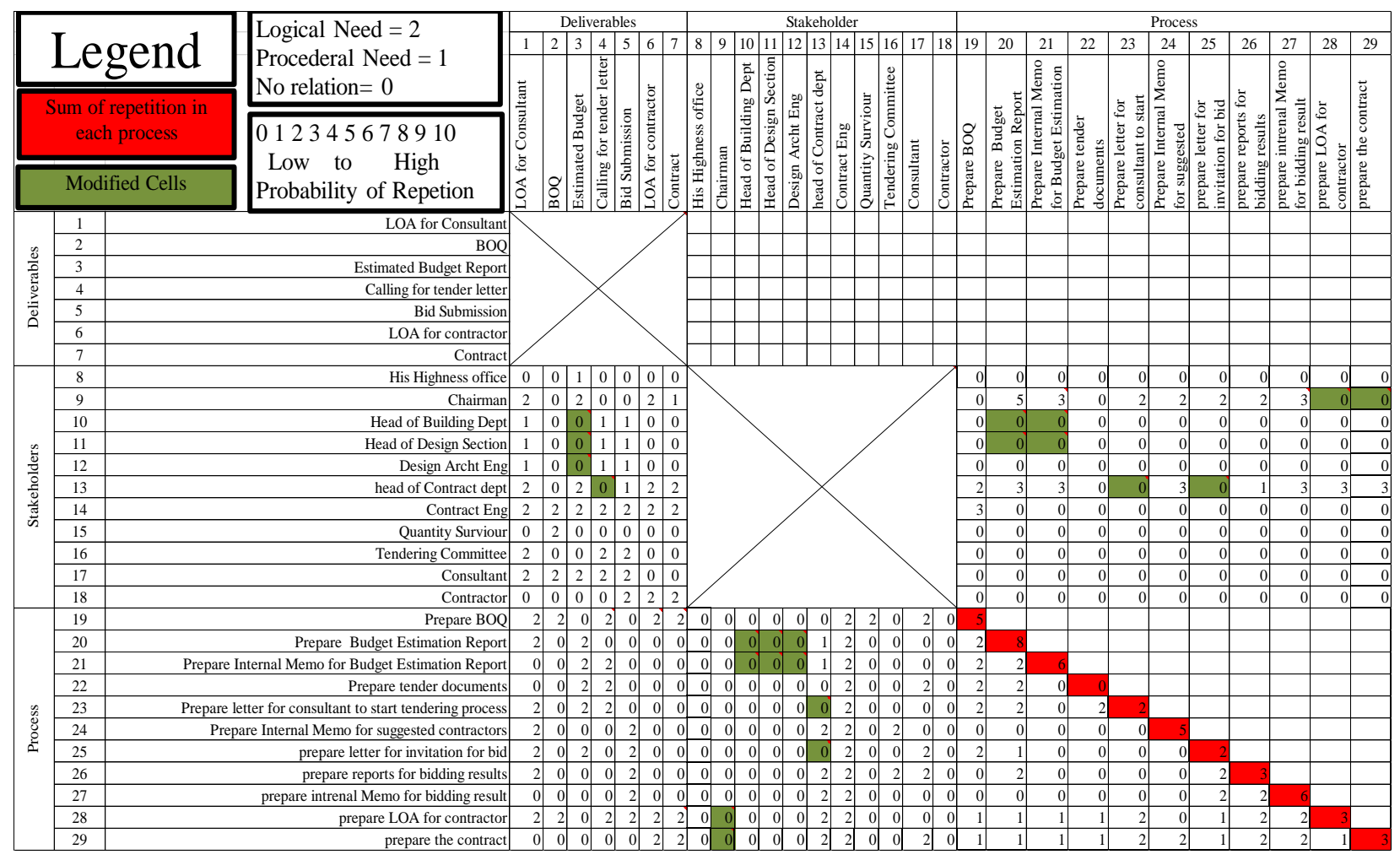

Fig. 5. MDM model after reengineered process

There were 10 procedural relationships which were adding no value to the project delivery were removed as mentioned in the shaded Process Vs Stakeholder DMM. As the result, the process repetitions and the overall time taken to accomplish the project delivery had been realized. Table 1 summarize the total number of repetition occur in each process in CTD department before and after the reengineering process. It shows that the total number of repetition has been reduced from 73 to 43 , which will help in reducing the delay in the CTD department.

Table 1. No of repetition before and after reengineering the processes

\begin{tabular}{|c|c|c|c|c|c|c|c|c|c|c|c|c|}
\hline Process & & $\begin{array}{l}\text { Prepare } \\
\text { BOQ }\end{array}$ & $\begin{array}{l}\text { Prepare } \\
\text { Budget } \\
\text { Estimation } \\
\text { Report }\end{array}$ & $\begin{array}{l}\text { Prepare } \\
\text { Internal } \\
\text { Memo for } \\
\text { Budget } \\
\text { Estimation } \\
\text { Report }\end{array}$ & $\begin{array}{l}\text { Prepare } \\
\text { letter for } \\
\text { consultant } \\
\text { to start } \\
\text { tendering } \\
\text { process }\end{array}$ & $\begin{array}{l}\text { Prepare } \\
\text { Internal } \\
\text { Memo for } \\
\text { suggested } \\
\text { contractors }\end{array}$ & $\begin{array}{l}\text { Prepare } \\
\text { letter for } \\
\text { invitation } \\
\text { for bid }\end{array}$ & $\begin{array}{l}\text { Prepare } \\
\text { reports } \\
\text { for } \\
\text { bidding } \\
\text { results }\end{array}$ & $\begin{array}{l}\text { Prepare } \\
\text { internal } \\
\text { Memo } \\
\text { for } \\
\text { bidding } \\
\text { result }\end{array}$ & $\begin{array}{l}\text { Prepare } \\
\text { LOA for } \\
\text { contractor }\end{array}$ & $\begin{array}{l}\text { Prepare } \\
\text { the } \\
\text { contract }\end{array}$ & Total \\
\hline \multirow{2}{*}{$\begin{array}{l}\text { No of } \\
\text { repetition }\end{array}$} & Before & 5 & 14 & 16 & 5 & 5 & 5 & 5 & 8 & 5 & 5 & 73 \\
\hline & After & 5 & 8 & 6 & 2 & 5 & 2 & 3 & 6 & 3 & 3 & 43 \\
\hline
\end{tabular}

\section{Summary and Discussion}

The process reengineering of any organization is inevitable due to the competitiveness as well as to improve the efficiency of the project delivery. Most of the public project delivery organizations are not performing the process reengineering regularly and there by left with bureaucratic procedures that does not match with the advancement of the modern industry. This paper attempted to capture the existing project delivery processes through a structured process reengineering procedure and demonstrated its applicability in delivering the public projects. The identification and the removal of process wastes, dysfunctionalities and redundancies are developed through a structured interview procedure to ascertain the facts. The obtained responses and the data were further utilized through a combination of process modelling tools, which are relevant to the study context. The paper used the activity theory to capture the in depth relationships among the various project system components such as the processes, stakeholders and the 
deliverables. The IDEF0 is used to identify the interactions of various processes along with its responsible stakeholders and their deliverables towards the successful project delivery. The generated IDEF0's help the development of MDM's to capture the existence of the relationships and identification of procedural/logical relationships. The combination of the above tools demonstrates a thorough understanding of the project delivery processes in SDPW. The procedural relationships are then qualified as value adding and non-value adding relationships. The procedural relationship which has no values other than the age-old bureaucratic procedure are considered as wastes and are removed. Further, the study validates the proposed methodology through 12 expert interviews and compared the before and after effect theoretically. The comparison shows that there are potential 30 revisions, which can be avoided and there by the delay can be mitigated. In addition, the results showed that the redundancy in this process has been reduced by eliminating the procedural relationships between the stakeholders and the deliverables and there by accelerating the internal processes. However, the actual implementation of the proposed reengineered procedure is yet to be tested due to the time constraints as well as the delayed approval for the procedural change by the competent authority. The proposed framework will be a guideline/ reference for similar business process reengineering exercise towards a public project delivery process in this region or in a similar context.

\section{References}

[1] H. C. Howard, R. E. Levitt, B. C. Paulson, J. G. Pohl, and C. B. Tatum, "Computer Integration: Reducing Fragmentation in AEC Industry," J. Comput. Civ. Eng., 2009. https://doi.org/10.1061/(ASCE)0887-3801(1989)3:1(18)

[2] Sharp, A., \& McDermott, P, "Workflow modeling: tools for process improvement and applications development". Artech House.,(2009)

[3] \& R. M. Dimitris Antoniadis, Francis Edum-Fotwe, Antony Thorpe, "Exploring complexity in construction projects," Proj. Manag. Adv. Train. Certif. Mediterr., no. May, pp. 1-6, 2008.

[4] D. Baccarini, “The concept of project complexity - A review,” Int. J. Proj. Manag., 1996.

[5] M. Hammer and J. Champy, Reengineering the Company - A Manifesto for Business Revolution. 2001.

[6] T. Davenport and J. Short, "The New Industrial Engineering: Information Technology and BusinessProcessRedesign," Sloan Manage. Rev., 1990.

[7] J. N. Lowenthal, "Reengineering the organization: a step-by-step approach to corporate revitalization,” Qual. Prog., 1994.

[8] M. Y. Cheng, H. S. Peng, C. M. Huang, and C. H. Chen, "KM-oriented business process reengineering for construction firms," Autom. Constr., vol. 21, no. 1, pp. 32-45, 2012. https://doi.org/10.1016/j.autcon.2011.05.010

[9] R. S. Aguilar-Savén, "Business process modelling: Review and framework," Int. J. Prod. Econ., vol. 90, no. 2, pp. 129-149, 2004. https://doi.org/10.1016/S0925-5273(03)00102-6

[10] Y. Engeström and R. Miettinen, "Activity theory: A well-kept secret," in Perspectives on activity theory, 1999.

[11] Y. Engestrom, "Activity theory as a framework for analyzing and redesigning work," Ergonomics, 2000.

[12] A. N. Leont'ev, "The Problem of Activity in Psychology," Sov. Psychol., 2011.

[13] D. Version, "design," 1993.

[14] L. S. Vygotsky, "Mind in society: The development of higher psychological processes.," Cambridge, MA: Harvard University Press. 1978.

[15] A.Akintola,S. S.Venkatachalam and D Root, " Understanding BIM's impact on professional work practice using activity theory ", Construction Management and Economics, pp. 1-21,2019. Available: httős://doi.org/10.1080/01446193.2018.1559338.

[16] G. R. Holt and A. W. Morris, "CVactivityTheory.pdf," Hum. Organ., 1993

[17] V. Kaptelinin and B. A. Nardi, "Activity Theory in a Nutshell," in Acting with technology : activity theory and interaction design, 2006

[18] G. R. Waissi, M. Demir, J. E. Humble, and B. Lev, "Automation of strategy using IDEF0 - A proof of concept," Oper. Res. Perspect., vol. 2, pp. 106-113, 2015.

[19] C. H. Kim, R. H. Weston, A. Hodgson, and K. H. Lee, “The complementary use of IDEF and UML modelling approaches," Comput. Ind., vol. 50, no. 1, pp. 35-56, 2003. https://doi.org/10.1016/S0166-3615(02)00145-8

[20] V. Grover, "Business process change: Reengineering concepts, methods and technologies," Long Range Plann., 2003.

[21] T. R. Browning, "Applying the design structure matrix to system decomposition and integration problems: A review and new directions," IEEE Trans. Eng. Manag., vol. 48, no. 3, pp. 292-306, 2001. https://doi.org/10.1109/17.946528

[22] S. D. Eppinger and T. R. Browning, Design structure matrix methods and applications. MIT press, 2012. 2012.

[23] Q. Yang, S. Kherbachi, Y. S. Hong, and C. Shan, "Identifying and managing coordination complexity in global product development project," Int. J. Proj. Manag., 2015.

[24] A.-W. Scheer, ARIS — Business Process Modeling. 2011.

[25] R. Schütte, Grundsätze ordnungsmäßiger Referenzmodellierung: Konstruktion konfigurations- und anpassungsorientierter Modelle. 1998.

[26] M. E. Sosa, S. D. Eppinger, and C. M. Rowles, "The Misalignment of Product Architecture and Organizational Structure in Complex Product Development," Manage. Sci., 2004.

[27] D. W. Stewart, P. N. Shamdasani, and D. W. Rook, Focus groups: Theory and practice ( 2nd ed.). 2007. 